\title{
Basal Cell Adhesion Molecule/Lutheran Protein The Receptor Critical for Sickle Cell Adhesion to Laminin
}

\author{
Manisha Udani, ${ }^{*}$ Qin Zen, ${ }^{*}$ Maisha Cottman, ${ }^{*}$ Nicole Leonard, ${ }^{*}$ Shawn Jefferson, ${ }^{\star}$ Carrie Daymont, ${ }^{*}$ George Truskey, \\ and Marilyn J. Telen* \\ *Division of Hematology, Department of Medicine, Duke University Medical Center, and ${ }^{\ddagger}$ School of Engineering, Duke University, \\ Durham, North Carolina 27710
}

\begin{abstract}
Sickle red cells bind significant amounts of soluble laminin, whereas normal red cells do not. Solid phase assays demonstrate that B-CAM/LU binds laminin on intact sickle red cells and that red cell B-CAM/LU binds immobilized laminin, whereas another putative laminin binding protein, CD44, does not. Ligand blots also identify B-CAM/LU as the only erythrocyte membrane protein(s) that binds laminin. Finally, transfection of murine erythroleukemia cells with human B-CAM cDNA induces binding of both soluble and immobilized laminin. Thus, B-CAM/LU appears to be the major laminin-binding protein of sickle red cells. Previously reported overexpression of B-CAM/LU by epithelial cancer cells suggests that this protein may also serve as a laminin receptor in malignant tumors. (J. Clin. Invest. 1998. 101:2550-2558.) Key words: sickle cell disease • erythrocyte (red blood cell) • laminin • Lutheran protein
\end{abstract}

\section{Introduction}

The hallmark of sickle cell disease (SCD) ${ }^{1}$ is episodic and painful vasoocclusion. This process appears to have a complex etiology, involving decreased deformability of erythrocytes, increased adhesive properties of sickle red blood cells (SS RBC), and activation of coagulation (1). Moreover, SS RBC demonstrate increased adhesion to both endothelial cells and to subendothelial matrix. Erythrocytes from patients homozygous for hemoglobin $(\mathrm{Hb}) \mathrm{S}$ adhere to both activated and nonactivated endothelial cells from both large and small vessels (2-4). In addition, release of various cytokines and adhesion of SS

Portions of this work were presented at the annual meeting of the American Society of Hematology, December 7-10, 1996.

Address correspondence to Marilyn J. Telen, Division of Hematology, Box 2615, Duke University Medical Center, Durham, NC 27710. Phone: 919-684-5378; FAX: 919-681-7688; E-mail: telen002@ mc.duke.edu

Received for publication 15 July 1997 and accepted in revised form 1 April 1998.

1. Abbreviations used in this paper: $\mathrm{AA} \mathrm{RBC}$, hemoglobin $\mathrm{A}$ red blood cell; ACD, acid citrate dextrose; AP, alkaline phosphatase; B-CAM, basal cell adhesion molecule; LU, Lutheran blood group; MEL, murine erythroleukemia; MFC, mean fluorescence channel; SCD, sickle cell disease; SS RBC, homozygous hemoglobin S RBC; TBST, Tris-buffered saline with Tween-20.

J. Clin. Invest.

(C) The American Society for Clinical Investigation, Inc. 0021-9738/98/06/2550/09 \$2.00

Volume 101, Number 11, June 1998, 2550-2558

http://www.jci.org
RBC effect damage to endothelial cells, causing endothelial cell retraction and apparent release into the circulation (5). This process has been proposed to lead to exposure of subendothelial matrix components, to which SS RBC also adhere to an abnormal degree. SS RBC vary among themselves in their ability to bind to both endothelial and extracellular matrix ligands, and the subpopulation of cells that adheres to a particular substrate may vary with the ligand and its receptor (6). Thus, reticulocytes may be the most adherent cells under some conditions and to some ligands, whereas the most dense cells may adhere best to other substrates (6).

Laminin is one of the predominant components of subendothelial matrix (7), and SS RBC adherence to laminin has recently been documented to be more marked than SS RBC adherence to thrombospondin (8). However, to date, no cell surface component of SS RBC or RBC with normal hemoglobin (AA RBC) has been shown to mediate the markedly increased adherence to laminin exhibited by intact sickle red cells. Normal RBC bear a number of known and putative adhesion proteins, including CD44 (the hyaluronan receptor) (9) LFA-3 (the CD2 receptor) (10) LW (ICAM-4, a receptor for various integrins) $(11,12)$, integrin-associated protein (CD47, a thrombospondin receptor) $(13,14)$, and neurothelin (Telen, M.J., unpublished data). In addition, RBC express a number of molecules thought likely to subserve adhesion functions, such as MIC2 (CD99) (15-17) and B-CAM/LU, the protein that carries Lutheran blood group antigens (18-20). Preliminary work by Platt and Gee (21) suggested that laminin bound to an $80-\mathrm{kD}$ protein of RBC membranes but did not identify the protein involved. More recently, Hillery et al. (8) found a plasma membrane lipid capable of binding laminin in both AA and SS RBC; however, it is not clear that this lipid is exposed at the cell surface, and its role in situ was not identified.

We have now used a number of techniques to identify the major laminin receptor of $\mathrm{AA}$ and $\mathrm{SS} \mathrm{RBC}$ as the protein that bears the Lutheran (LU) blood group antigens. The Lutheran blood group antigens reside on two proteins of 85 and $78 \mathrm{kD}$ (22). These two proteins contain identical extracellular domains and differ only in the length of their cytosolic tails (20, 23). B-CAM/LU is a member of the Ig superfamily of proteins, many of which have adhesion functions. We have now shown that B-CAM/LU expressed by SS RBC binds both soluble and immobilized laminin. Expression of B-CAM/LU antigens is increased on SS RBC, and it is the RBC with highest B-CAM/ $\mathrm{LU}$ expression that bind significant amounts of soluble laminin. Finally, expression of B-CAM cDNA in transfected murine erythroleukemia cells induces both soluble laminin binding as well as adhesion to immobilized laminin under flow conditions.

\section{Methods}

Collection, storage, and preparation of $R B C$. In general, blood samples from patients with sickling hemoglobinopathies and from normal 
controls were collected into citrate tubes and stored at $4{ }^{\circ} \mathrm{C}$ in acid citrate dextrose (ACD) for no longer than $1 \mathrm{wk}$. For studies of the level of expression of Lutheran blood group antigens, blood from AfricanAmerican and Caucasian normal donors was collected from segments attached to donated ACD-anticoagulated units of blood and was also used within $1 \mathrm{wk}$ of collection. All RBC were washed three times in PBS ( $\mathrm{pH}$ 7.4), with removal of the plasma and buffy coat, before use.

Antibodies. mAbs used for this study included A3D8 (antiCD44) (24); anti-Lu ${ }^{\mathrm{b}}$ (mAb LM342/767:31; generously provided by Robin Fraser, Scottish National Blood Transfusion Service, Glasgow, United Kingdom); and anti-B-CAM/LU (mAb $8 \mathrm{H} 3$, produced as previously described) (25). In all studies involving intact cells, mAbs were used at saturating dilutions of either ascitic fluid or tissue culture supernate. P3x63/Ag8 (P3) supernatant or ascites fluid was used as a nonreactive control murine immunoglobulin (Ig) for work using mAbs (26). Rabbit anti-human laminin was obtained from GIBCO BRL (Gaithersburg, MD) and used at a dilution of 1:500. Alkaline phosphatase (AP)-linked secondary antibodies were obtained from Jackson Immunoresearch (West Grove, PA), as were FITC-conjugated antibodies. Phycoerythrin-conjugated goat anti-mouse Ig and goat anti-rabbit Ig were obtained from Sigma Immunochemicals (St. Louis, MO).

Flow cytometric assays. RBC were collected and stored as described above. For flow cytometric assays, packed RBC were diluted in PBS to a concentration of $1 \%(\mathrm{vol} / \mathrm{vol})$. In general $50 \mu \mathrm{l}$ of RBC suspension were incubated with $50 \mu \mathrm{l}$ of either a saturating dilution of $\mathrm{mAb}$ or $3 \mu \mathrm{g} / \mathrm{ml}$ human placental laminin (GIBCO BRL). Laminin binding assays were performed either at room temperature or at $37^{\circ} \mathrm{C}$, whereas all other incubations were performed at room temperature. For assays of reactivity with $\mathrm{mAbs}$, cells were incubated with the primary antibody for $30 \mathrm{~min}$, washed twice with $1 \mathrm{ml} \mathrm{PBS,} 1 \mathrm{gram} / \mathrm{dl}$ BSA, and then incubated with $50 \mu$ fluorochrome-conjugated antibody to murine Ig. For laminin binding assays, the secondary antibody was rabbit anti-human laminin. After 30-min incubation and repeated washes, $50 \mu \mathrm{l}$ of a fluorescein-conjugated anti-rabbit Ig was added. After incubation, all samples were again washed as previously described, and cells were then resuspended to $0.5 \mathrm{ml}$ in PBS, $0.2 \%$ formaldehyde. Fluorescein-stained cells were then stored at $4^{\circ} \mathrm{C}$ in the dark until flow cytometric analysis, performed on an Orthocytoron Absolute (Ortho Diagnostic Systems, Inc., Raritan, NJ).

For two-color immunofluorescence assays examining B-CAM/ LU expression and laminin binding simultaneously, cells were first stained as described above for laminin binding. Cells were then incubated with anti- $\mathrm{Lu}^{\mathrm{b}}$, washed, and incubated with phycoerythrin-conjugated anti-mouse Ig, as described for single color fluorescence. Negative controls consisted of the same controls used in single color fluorescence assays, namely P3 myeloma protein, followed by phycoerythrin-conjugated anti-mouse Ig for anti- $\mathrm{Lu}^{\mathrm{b}}$, and BSA followed by rabbit anti-laminin and fluorescein-conjugated anti-rabbit Ig for laminin binding. To determine and compensate for any crossover between spectra for fluorescein and phycoerythrin, cells stained for only one marker ( $\mathrm{Lu}^{\mathrm{b}}$ or laminin binding), with and without staining using the negative control for the other marker, were also analyzed in twocolor mode.

In certain experiments, cells were stained to measure laminin binding but with phycoerythrin-conjugated anti-rabbit Ig and were not fixed as above. Instead, $0.5 \mathrm{ml}$ Retic-Count ${ }^{\mathrm{TM}}$ (Becton Dickinson, San Jose, CA) was added to phycoerythrin-stained cells, incubated for $30 \mathrm{~min}$ at room temperature, and analyzed by flow cytometry within $3 \mathrm{~h}$. All two-color flow cytometric analyses were performed on a FACScan (Becton Dickinson).

Statistical analysis of data derived from flow cytometry was performed using unpaired $t$ tests.

Solid phase assays. We performed solid phase assays using both soluble and immobilized laminin to demonstrate that B-CAM/LU is the $\mathrm{RBC}$ laminin receptor $(25,27)$. When soluble laminin binding was assayed, $80 \mu \mathrm{l}$ of a $10 \%$ suspension of RBC in PBS was incubated simultaneously with $80 \mu \mathrm{l}$ of a mAb (A3D8, P3, or LM342/767:31) and
$40 \mu \mathrm{l}$ of $60 \mu \mathrm{g} / \mathrm{ml}$ laminin or BSA for $30 \mathrm{~min}$ at $37^{\circ} \mathrm{C}$. Cells were then washed with PBS, incubated with $80 \mu \mathrm{l}$ of a 1:250 dilution of rabbit antilaminin, washed again, and then solubilized in $2.5 \%$ Triton X-100 solution as previously described $(25,27)$. Lysates were then incubated in wells previously coated with goat anti-mouse Ig. Unbound proteins were then removed by washing repeatedly with Tris-buffered saline, $0.05 \%$ Tween-20 (TBST), and wells were developed with alkaline-phosphatase (AP)-conjugated goat anti-rabbit Ig to detect wells in which murine monoclonal antibody and laminin bound to the same protein(s). Positive reactions were detected using the $p$-nitrophenyl phosphate disodium Phosphatase Substrate (Sigma Immunochemicals) at $1 \mathrm{mg} / \mathrm{ml}$ and detected using spectrophotometry at $405 \mathrm{~nm}$.

For assays measuring the binding of B-CAM/LU to immobilized laminin, wells were precoated with $100 \mu \mathrm{l}$ of $3 \mu \mathrm{g} / \mathrm{ml}$ human laminin or BSA in carbonate buffer, and then $1 \%$ BSA in TBST was added to block remaining available binding sites. $\mathrm{RBC}$ were incubated with either monoclonal anti-Lu ${ }^{\mathrm{b}}$, anti-CD44, or the nonreactive P3 murine myeloma protein. For assays using MEL cells, cells were suspended at $2 \times 10^{8}$ cells $/ \mathrm{ml}$ and treated exactly as RBC thereafter. After washing, cells were lysed as above, and lysates were incubated in wells coated with laminin or BSA. After repeated washing, laminin-binding proteins recognized by murine antibodies were detected using AP-conjugated anti-mouse Ig, giving a positive reaction if the $\mathrm{mAb}$ bound to a protein that bound to immobilized laminin. These assays used the same detection system described above.

Western blots. RBC membrane proteins were prepared from RBC ghosts as previously described and separated by SDS-polyacrylamide gel electrophoresis (28-30). After transfer to nitrocellulose (31) and blocking of nonspecific binding sites with $10 \%$ dried milk powder in TBST, lanes containing membrane proteins from AA or SS RBC and from AA RBC with various blood group phenotypes were reacted at $4^{\circ} \mathrm{C}$ with either mAbs or a solution containing $3 \mu \mathrm{g} / \mathrm{ml}$ human laminin. Detection of laminin binding utilized the same antibodies as those used for solid phase assays. Bands reacting with mAbs were detected using AP-conjugated goat anti-mouse Ig, while proteins binding laminin were detected using AP-conjugated goat anti-rabbit Ig. Blots were developed using 5-bromo-4-chloro-3-indolyl-phosphate and nitro blue tetrazolium as enzyme substrate (Promega Corp., Madison, WI).

Expression of B-CAM cDNA in murine erythroleukemia cells. B-CAM cDNA was constructed by PCR using appropriate $5^{\prime}$ and $3^{\prime}$ oligonucleotide primers (18) from an incomplete LU cDNA kindly provided by David Anstee (Bristol, United Kingdom). B-CAM cDNA was cloned into pcDNA3.1(-) (Invitrogen Corp., Carlsbad, CA) at the EcoRV site in an orientation allowing expression via the cytomegalovirus promoter. MEL cells were transfected by electroporation as previously described (9), except that transfected cells were grown in RPMI-1640 media supplemented with $10 \%$ fetal calf serum and $500 \mu \mathrm{g} / \mathrm{ml}$ G418 (Life Technologies, Inc., Gaithersburg, MD), followed by selection of cells strongly expressing the $\mathrm{Lu}^{\mathrm{b}}$ blood group antigen by sterile cell sorting using a Becton-Dickinson FACStarplus (Mountain View, CA).

Flow chamber assays. We used flow chambers to quantitate the adhesion to immobilized laminin of SS and AA RBC, as well as of MEL cells transfected with B-CAM/LU cDNA constructs. Clear glass slides were precoated with laminin overnight $(10 \mu \mathrm{g} / \mathrm{ml}$ in PBS). Slides were then fit into a variable height flow chamber, as previously described (32). The flow chamber was mounted on the stage of an inverted phase contrast microscope (Diaphot; Nikon Inc., Melville, NY) and observed using a video camera (Series 70; Dage-MTI Inc., Michigan City, IN) attached to the microscope and connected to a Macintosh IIx computer. Cells suspended in PBS were inserted into the flow chamber and allowed to adhere to the slide for $15 \mathrm{~min}$ without flow. Before exposure to flow, a minimum of three fields at each of five different locations along a line oriented normal to future flow were examined for the number of adherent cells. Then, a 100-ml syringe mounted on a calibrated syringe pump was attached to the inlet port of the chamber and flow started, such that the shear stress along 
the slide in the flow chamber would range from $0.2-15.0$ dynes $/ \mathrm{cm}^{2}$. After exposure to flow for $3 \mathrm{~min}$, the 15 or more fields of cells previously identified were again examined and the number of cells counted. Finally, the fraction of cells remaining attached at a given location was calculated as the ratio of cell attached after exposure to flow divided by the cells per field before flow. The channel height $\mathrm{H}$ was measured at each of the locations, and the wall shear stress was calculated as:

$\tau_{\mathrm{W}}=\frac{6 \mu \mathrm{Q}}{\mathrm{wH}(\mathrm{x})^{2}}$

where $\tau_{\mathrm{w}}=$ wall shear stress $\left(\mathrm{dyne} / \mathrm{cm}^{2}\right) ; \mathrm{Q}=$ volumetric flow rate $\left(\mathrm{cm}^{3} / \mathrm{s}\right) ; \mu$ is media viscosity, $w$ is the width of the flow channel, and $\mathrm{H}(\mathrm{x})$ is the height of the flow chamber as a function of position along the microscope slide (32). The critical shear stress $\left(\tau_{\mathrm{c}}\right)$ was defined as the applied shear stress for which $50 \%$ of the cells remained adherent. For RBC, cells were stored and treated as described above and studied suspended in PBS. For MEL cells, cells were stored in tissue culture media at $37^{\circ} \mathrm{C}$, with $5 \% \mathrm{CO}_{2}$ until immediately before application to the flow chamber. Cells were then quickly washed and resuspended in PBS for the experiment.

\section{Results}

$S S R B C$ bind soluble laminin markedly more than do $A A$ $R B C$. Previous work has suggested that soluble laminin bound to one or more proteins of SS RBC plasma membranes immobilized on nitrocellulose (21). We therefore sought to determine if binding of soluble laminin to intact SS RBC could be measured by flow cytometry and whether SS RBC would show increased binding of soluble laminin similar to the previously described increased binding to immobilized laminin (8). We reasoned that a similar increase in binding of soluble laminin would suggest that binding of RBC to soluble and immobilized laminin were likely to be through the same receptor.

In initial experiments, we compared the binding of soluble laminin to intact SS and AA RBCs at room temperature. Under those conditions, we examined 20 samples from 16 patients with hemoglobin SS, 13 samples from 11 patients with hemo-

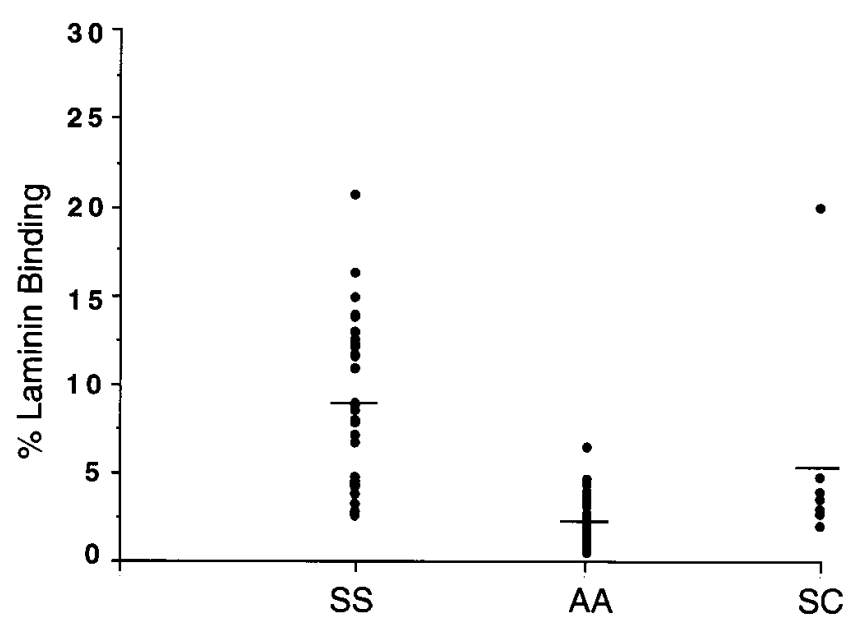

Figure 1. Binding of soluble laminin to red cells. Soluble laminin was incubated with RBC containing the types of hemoglobins indicated, and laminin binding was detected by rabbit antilaminin, followed by FITC-conjugated anti-rabbit Ig. At both $22^{\circ} \mathrm{C}$ (data not shown) and $37^{\circ} \mathrm{C}$, SS and SC RBC bound significantly more laminin than did AA RBC. Horizontal lines indicate mean percent cells binding laminin. globin SC, and 23 samples from 15 normal control subjects with no known hemoglobinopathy. None of the subjects whose $\mathrm{RBC}$ were examined had been recently transfused (within $1 \mathrm{mo}$ ) or were receiving hydroxyurea therapy. In these experiments, we found that an average of $7.495 \pm 0.935 \%$ (SEM) of SS RBC bound laminin, compared to $2.535 \pm 0.396 \%$ of AA RBC $(P<$ $0.001)$. In contrast, $5.269 \pm 1.055 \%$ of SC RBC bound laminin $(P=0.006$ compared to AA RBC). We then examined laminin binding at $37^{\circ} \mathrm{C}$ rather than at $22^{\circ} \mathrm{C}$. We examined 29 samples from 25 SS RBC donors, 57 samples from 36 AA $\mathrm{RBC}$ donors, and nine samples from five SC RBC donors in experiments at $37^{\circ} \mathrm{C}$. An average of $8.776 \pm 0.855 \%$ SS RBC bound laminin, compared to $2.356 \pm 0.151 \%$ AA RBC $(P<$ 0.001 ), thus confirming that there was a statistically significant difference in laminin binding by SS and AA RBC at physiologic temperature as well (Fig. 1). At $37^{\circ} \mathrm{C}$, an average of $5.211 \pm 1.868 \%$ SC RBC bound laminin $(P=0.001$ compared to AA RBC).

SS RBC adhere to immobilized laminin despite high shear stress. When SS RBC and AA RBC were compared in the flow chamber assay, SS RBC from multiple donors bound to immobilized laminin despite high shear stresses. SS RBC exhibited adherence to laminin with critical shear stresses of up to 15 dynes $/ \mathrm{cm}^{2}$ (Fig. 2). Normal RBC, on the other hand, never showed adhesion with critical shear stresses $>2$ dynes $/ \mathrm{cm}^{2}$ and usually bound so weakly that critical shear stress was measured as $<1$ dyne $/ \mathrm{cm}^{2}$ (Fig. 2). However, some SS RBC examined showed relatively low adhesion to laminin in this system, so that while many patient's RBC exhibited marked adhesion to immobilized laminin, RBC from other patients exhibited adhesive properties within the normal range or only moderately increased (e.g. critical shear stress of $\sim 5$ dynes $/ \mathrm{cm}^{2}$ ). In this way, the flow chamber assay of adhesion to immobilized laminin exhibited a patient-to-patient variability similar to that seen in the flow cytometric assay, in which some patients' cells gave results that fell within the normal range (Fig. 1).

Identification of the protein binding soluble laminin in Western blots. We found that laminin bound to RBC membrane protein with an approximate molecular weight of 80,000 and the reactive protein was visualized as a doublet. We therefore explored the possibility that laminin was binding to CD44, a widely expressed RBC membrane protein that has previously been described as able to bind laminin (33). In RBC membranes, CD44 occurs as a predominant $80-\mathrm{kD}$ protein accompanied by a slightly smaller protein band due to the presence of an isoform missing a portion of CD44 exon 5 (Cobourn, S.D., and M.J. Telen, unpublished data). However, we were unable to demonstrate that purified CD44 (34) bound laminin in solid phase assays or that cells transfected with either form of CD44 cDNA (9) were thereby induced to bind laminin (data not shown). We therefore sought to identify whether another protein of somewhat similar molecular weight might be the laminin receptor identified in Western blots.

LU antigens reside on a membrane glycoprotein expressed as two spliceoforms of 78 and $85 \mathrm{kD}(20,23)$. These two proteins both bear the antithetical antigens $\mathrm{Lu}^{\mathrm{a}}$ and $\mathrm{Lu}^{\mathrm{b}}$, as well as a number of other high- and low-frequency blood group antigens. RBC can have a LU antigen-negative $[\mathrm{Lu}(\mathrm{a}-\mathrm{b}-)]$ phenotype via several mechanisms. In the autosomal dominant, or $\operatorname{In}(\mathrm{Lu}) \mathrm{Lu}(\mathrm{a}-\mathrm{b}-)$, phenotype, a thus far uncharacterized genetically dominant mechanism causes markedly reduced expression of both LU protein as well as CD44 (34). However, in 


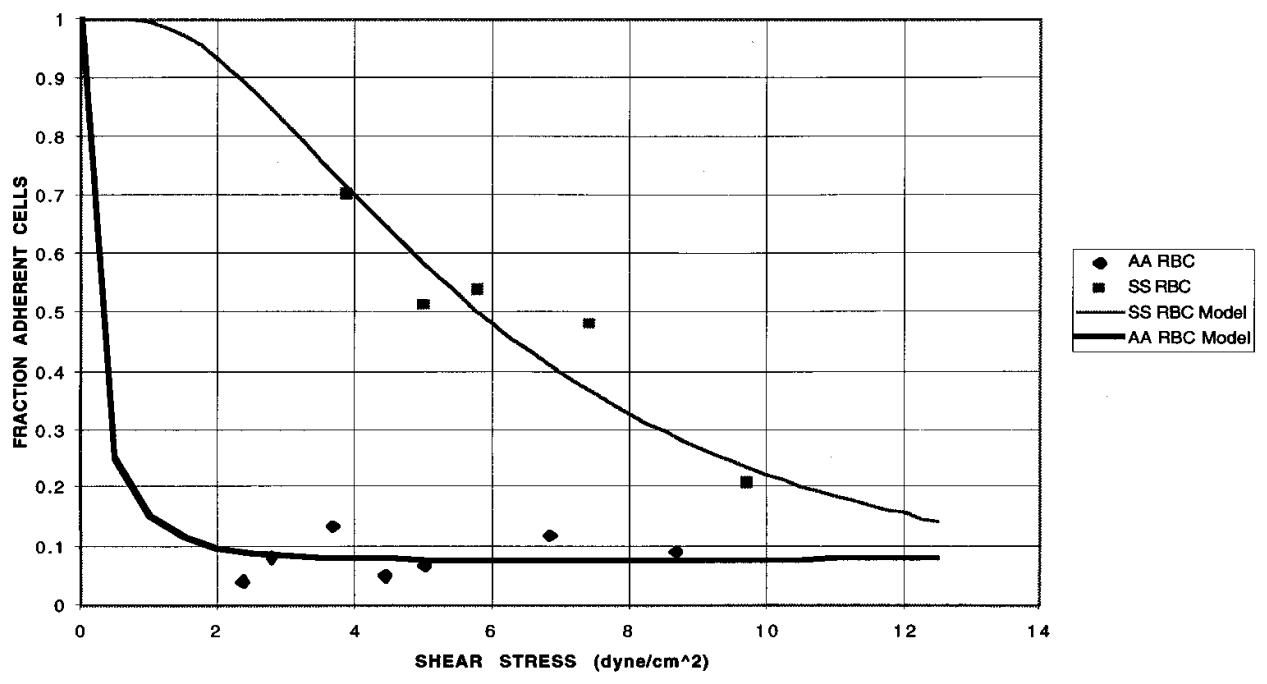

Figure 2. Adhesion of normal and SS RBC to immobilized laminin. Laminin was applied to glass slides and $\mathrm{RBC}$ were allowed to adhere in the absence of flow and then exposed to flow to determine the shear stress required to detach adherent cells. Normal (AA) RBC detached when exposed to low shear stresses, while SS RBC typically remained adherent unless exposed to high shear stresses. Critical shear stress, i.e., the shear stress required to remove $50 \%$ of the cells, was $\sim 5$ dyne $/ \mathrm{cm}^{2}$ for the SS RBC used in this experiment, while the majority of AA RBC detached when exposed to a shear stress of $<1$ dyne $/ \mathrm{cm}^{2}$. Multiple other AA and SS RBC gave similar results, as discussed in the text. the recessive $\mathrm{Lu}(\mathrm{a}-\mathrm{b}-)$ phenotype, $\mathrm{B}-\mathrm{CAM} / \mathrm{LU}$ expression is totally absent, presumably due to alteration of the $B-C A M / L U$ gene, while CD44 expression is normal (35). We used RBC membrane proteins of cells with these Lutheran blood group antigen-negative phenotypes to determine if presence or absence of B-CAM/LU protein correlated with ability or inability to bind laminin in Western blots. Results of staining membrane proteins from RBC with these phenotypes, as well as from SS and AA RBC with normal LU blood group antigen expression, demonstrated that absence of B-CAM/LU protein was associated with absence of laminin binding, thus strongly suggesting that it was B-CAM/LU protein that bound laminin (Fig. 3). Normal expression of CD44 without B-CAM/LU was not sufficient for laminin binding. In addition, membrane B-CAM/LU protein from SS RBC appeared to bind more laminin than did an equal amount of protein from AA RBC. This increase was more evident for the 78 - than the $85-\mathrm{kD}$ protein band.

Identification of B-CAM/LU protein as the protein binding both soluble and immobilized laminin. To confirm further the identity of the SS RBC protein binding soluble laminin, we adapted the MAIEA (monoclonal antibody-specific immobilization of erythrocyte antigen) assay of Petty (27) to one involving ligand (i.e., laminin) binding, as described in Methods. Intact SS RBC were coincubated with soluble laminin and one of several monoclonal antibodies to surface membrane pro-
$\mathrm{kD}$

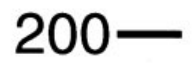

$97.4-$

$69-$

$46-$

$30-$

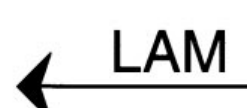

$\checkmark$
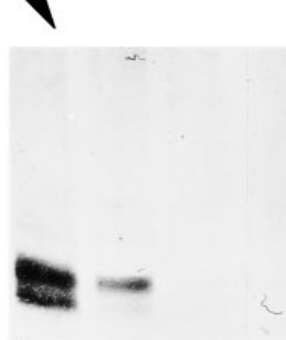

$\rightarrow$

LU
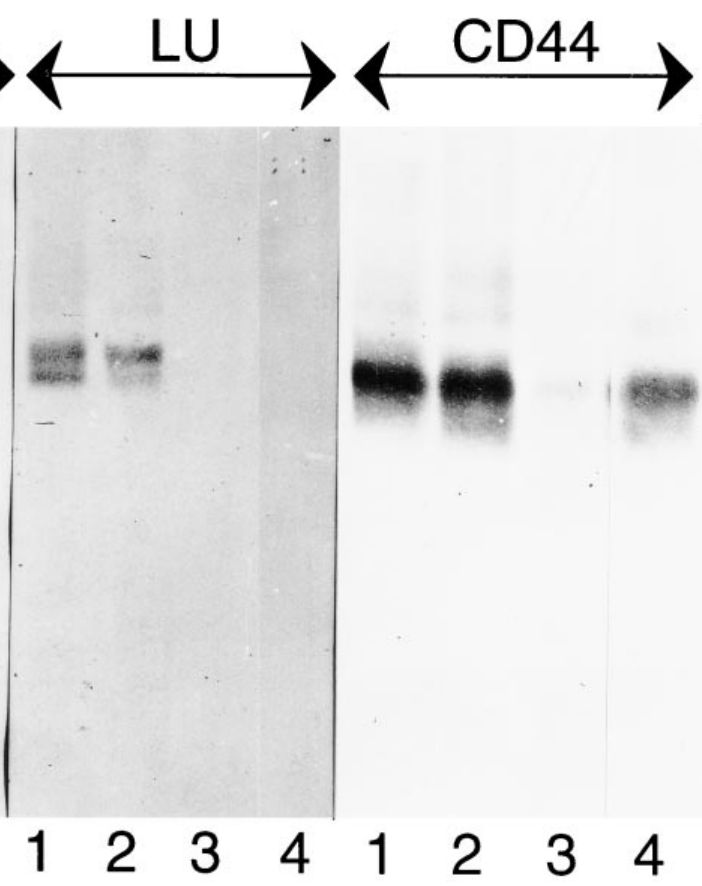

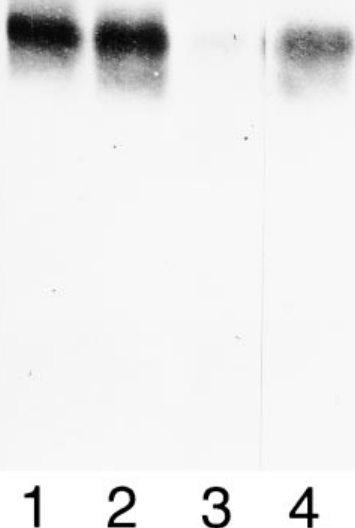

Figure 3. Soluble laminin reacts with two RBC membrane protein bands of 85 and $78 \mathrm{kD}$, absent from $\mathrm{Lu}(\mathrm{a}-\mathrm{b}-)$ RBC. Solubilized RBC membrane proteins were separated by SDS-PAGE and transferred to nitrocellulose, as described in Methods. Duplicate sets of lanes were reacted with either laminin, antiB-CAM/LU, or anti-CD44, and binding of these antibodies was detected with the appropriate secondary antibodies. Lanes contained membrane proteins from cells with the following phenotypes: (1) SS RBC: $\mathrm{Lu}(\mathrm{a}-\mathrm{b}+), \mathrm{CD} 44+;$ (2) AA RBC: $\mathrm{Lu}(\mathrm{a}-\mathrm{b}+)$, CD44+ (normal phenotype); (3) AA RBC: $\mathrm{Lu}(\mathrm{a}-\mathrm{b}-)$, CD44 ${ }^{\text {weak }}$ (dominant In[Lu]); (4) AA RBC: $\mathrm{Lu}(\mathrm{a}-\mathrm{b}-)$, $\mathrm{CD} 44+$ (recessive $\mathrm{Lu}[\mathrm{a}-\mathrm{b}-]$ phenotype). Laminin reacted with protein bands of molecular weight consistent with B-CAM/LU and absent from both $\mathrm{Lu}(\mathrm{a}-\mathrm{b}-$ ) (Lutheran null phenotype) RBC. 

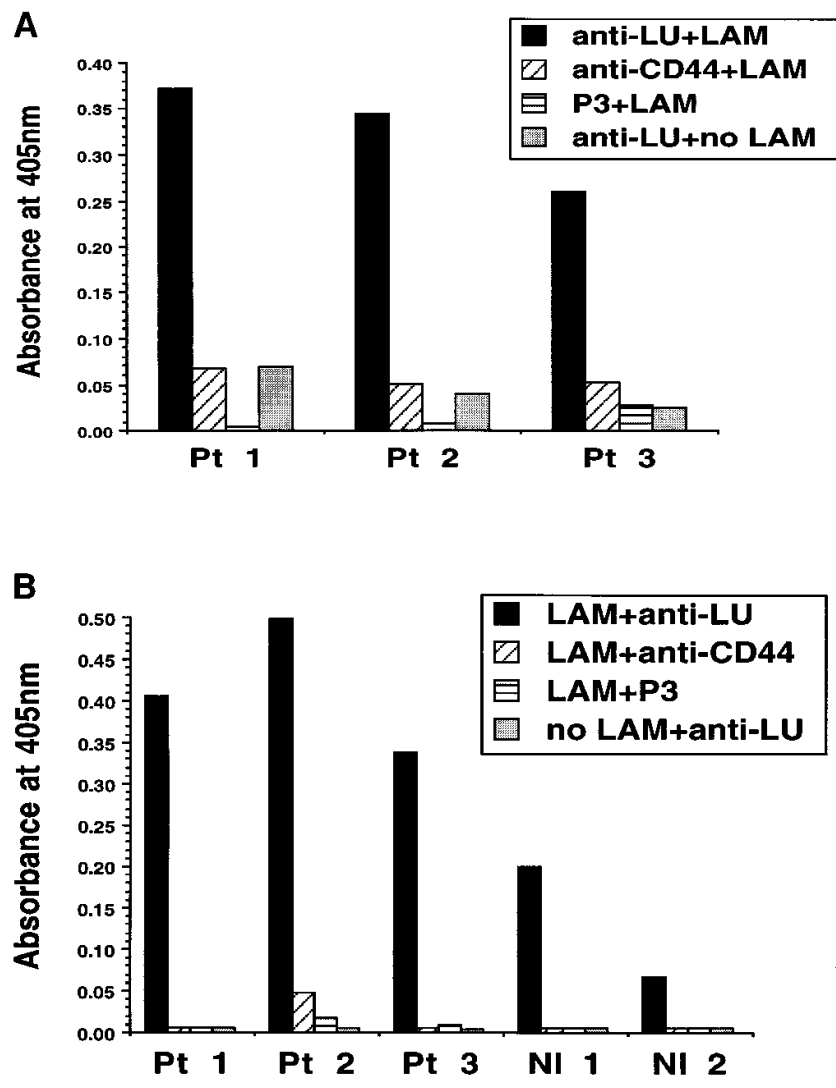

Figure 4. Solid phase capture assays identifying B-CAM/LU as the laminin receptor. $(A) \mathrm{SS} \mathrm{RBC}$ were reacted with soluble laminin $(L A M)$ and murine $\mathrm{mAb}$ to a membrane protein component $(\mathrm{CD} 44$ or B-CAM/LU) or a negative control murine Ig (P3), washed, coated with rabbit antilaminin, and then solubilized, as described in Methods. Increased absorbance indicates cocapture of laminin/rabbit antilaminin complexes and the $\mathrm{mAb}$ to a membrane protein. Data shown are from three representative SS RBC samples from different patients $(P t)$. AA RBC showed no reactivity (data not shown). (B) SS $\mathrm{RBC}$ were reacted with a murine $\mathrm{mAb}$ to a membrane component, solubilized, and reacted with immobilized laminin, as described in Methods. Increased absorbance indicates binding of a mAb target protein to immobilized laminin. Data shown are for three SS RBC patients and for two AA RBC controls $(\mathrm{Nl})$. All bars represent the mean of assays performed in triplicate. In general, triplicates did not vary $>10 \%$ from the mean.

teins, then lysed with detergent. Lysate was then incubated in wells coated with anti-mouse Ig. Laminin was cocaptured with membrane protein only when an antibody to B-CAM/LU was used to coat intact RBC (Fig. $4 A$ ). Antibodies to other surface proteins, such as CD44, did not appear to react with a laminin receptor in this assay. AA RBC did not show significant binding of laminin to B-CAM/LU protein in the solid phase assay using soluble laminin (data not shown).

Since it has been hypothesized that immobilized laminin may display different binding surfaces than laminin in solution, we also determined which SS RBC membrane protein(s) bound immobilized laminin. This assay involved solubilization of RBC membrane proteins coated with antibody to membrane proteins before incubation with immobilized laminin; it again showed similar results (Fig. $4 \mathrm{~B}$ ). Antibodies to B-CAM/
LU identified proteins bound to laminin, while antibodies to other membrane proteins, including CD44, did not. Proteins from SS RBC membranes gave more strongly positive results than proteins from AA RBC membranes, as would have been predicted from flow cytometric laminin-binding assays. These results therefore confirm that $\mathrm{B}-\mathrm{CAM} / \mathrm{LU}$ protein binds both soluble and immobilized laminin.

Level of expression of $B-C A M / L U$ protein is increased on SS RBC and correlates with the ability to bind laminin. To explore why laminin appeared to bind better to B-CAM/LU on SS than AA RBC, we used immunofluorescence and flow cytometry to assess the level of expression of $\mathrm{B}-\mathrm{CAM} / \mathrm{LU}$ protein on SS RBC. We compared SS RBC to RBC samples from African-American and Caucasian controls who qualified as blood donors (and therefore were likely to have either hemoglobin AA or AS). African-Americans with hemoglobin SS (19 samples from 18 patients) reacted with anti-B-CAM/LU
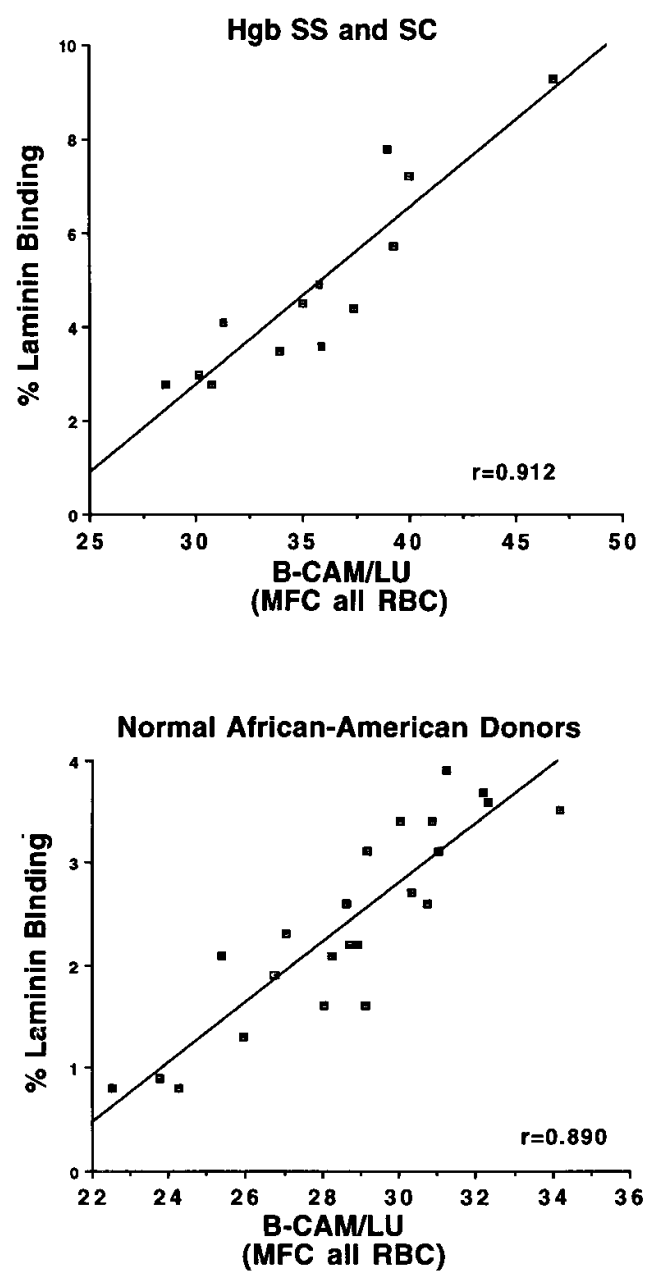

Figure 5. Relationship of laminin binding to B-CAM/LU expression among African-Americans with normal hemoglobin and hemoglobin SS and SC. All samples were analyzed in a single experiment, using $\mathrm{mAb} 8 \mathrm{H} 3$ to B-CAM/LU and soluble laminin, as described in Methods. The correlation ( $r$ value) between the percent of cells binding laminin and the mean fluorescence channel $(M F C)$ of cells reacted with anti-B-CAM/LU is indicated in each graph. Similar results were also obtained using the anti-Lu' ${ }^{\mathrm{b}}$ Mab LM342/767:31 (data not shown). 
A
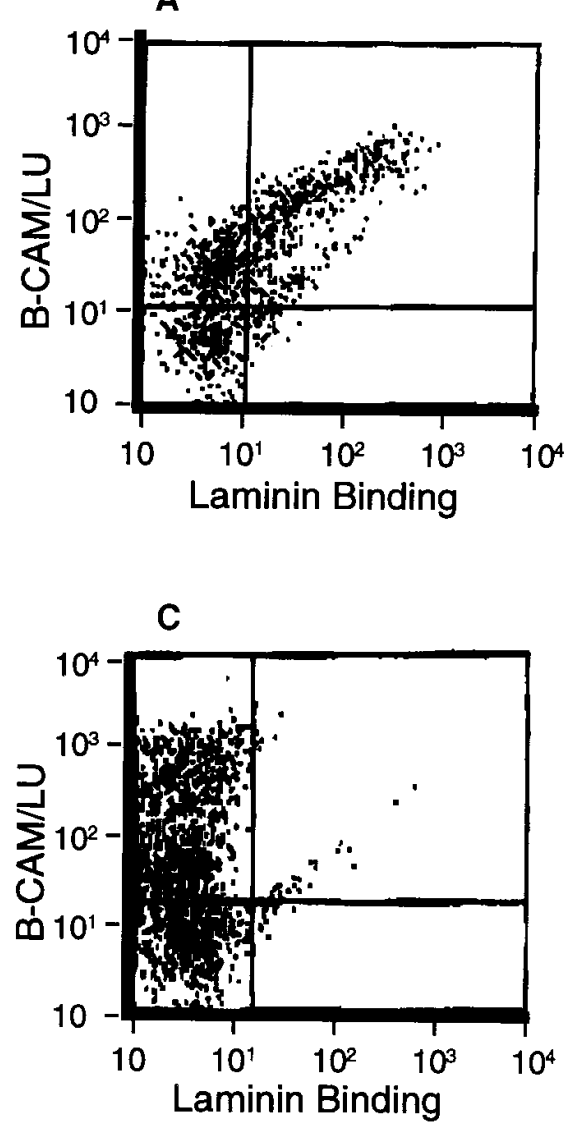

B
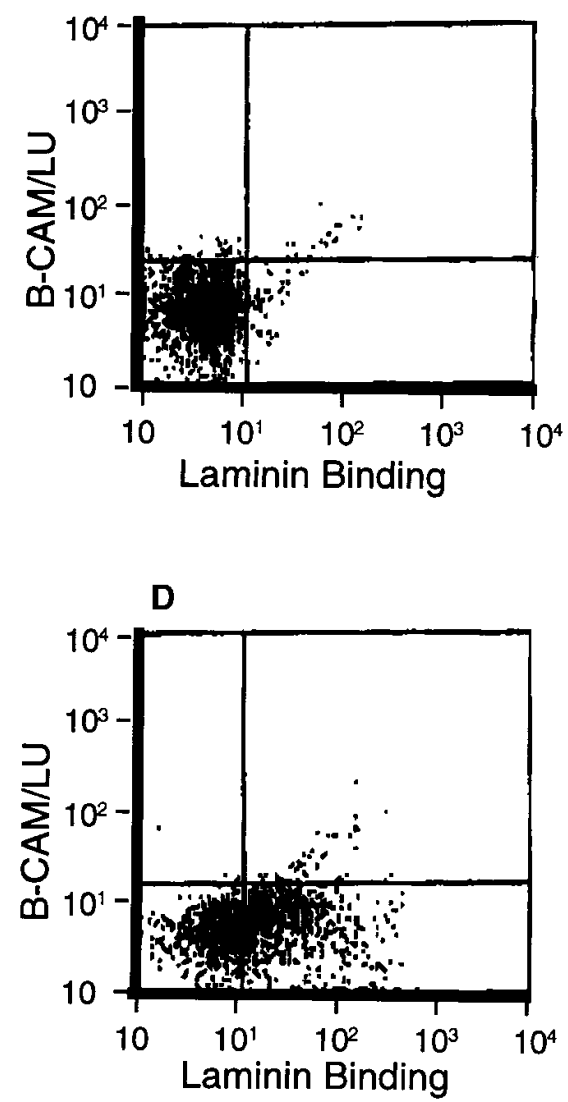

Figure 6. Two-color immunofluorescence correlation of laminin binding with B-CAM/LU expression. Fluorescence due to binding of laminin, followed by rabbit antilaminin, is graphed along the $\mathrm{X}$ axis, while fluorescence due to binding of anti$\mathrm{B}-\mathrm{CAM} / \mathrm{LU}$ (anti-Lu ${ }^{\mathrm{b}}$ ) is graphed along the $\mathrm{Y}$ axis. $(A)$ staining with both laminin/ antilaminin and anti-B-CAM/LU; $(B)$ double negative control, consisting of cells stained with BSA, followed by rabbit antilaminin and FITC-anti-rabbit Ig, as well as P3 myeloma protein, followed by phycoerythrin-conjugated anti-mouse Ig; $(C)$ anti-B-CAM/LU only; $(D)$ laminin/antilaminin only. Regions along the $\mathrm{x}$ and $\mathrm{y}$ axes were drawn based on analysis of the double negative control, so that $\leq 2.1 \%$ of negative control cells fell within any "positive" region. antibodies more strongly than did RBC from normal Caucasian and African-American controls (33 samples from 26 donors). Using a monoclonal antibody to B-CAM/LU protein, the mean fluorescence channel (MFC) for all RBC in SS RBC samples was $66.93 \pm 2.83$, while the average MFC for AA RBC samples was $56.91 \pm 1.98(P=0.005)$. Caucasian and AfricanAmerican blood donors with normal phenotypes had equivalent levels of red cell B-CAM/LU expression (average MFC $60.36 \pm 4.87$ and 55.98 \pm 2.16 , respectively, $P=0.375$ ).

We then attempted to determine whether there was a correlation between the degree of laminin binding and the expression of B-CAM/LU. For AA, SC, and SS RBC, the degree of fluorescence obtained using $\mathrm{mAb}$ to $\mathrm{B}-\mathrm{CAM} / \mathrm{LU}$ protein was directly proportional to the percent of $\mathrm{RBC}$ binding laminin, with $r \geq 0.89$ for both AA and SS+SC populations (Fig. 5). This observation is further support of the hypothesis that $\mathrm{B}-\mathrm{CAM} / \mathrm{LU}$ protein is indeed the major receptor for laminin on red cells.

Laminin-binding $R B C$ are those that express $B-C A M / L U$ most strongly. Although all RBC express B-CAM/LU, the range of expression is variable from cell-to-cell when analyzed by flow cytometry. To determine if the level of expression of B-CAM/LU on individual cells correlated with their ability to bind soluble laminin, two-color immunofluorescence assays were performed. These assays showed a double-positive population of cells characterized by both high B-CAM/LU expression and laminin binding (Fig. $6 A$ ). $91.9 \%$ of cells in the regions indicating positivity for laminin binding were in the region indicating high $\mathrm{B}-\mathrm{CAM} / \mathrm{LU}$ expression, despite the fact that $28 \%$ of all cells showed low B-CAM/LU expression. Furthermore, a plot of the double-positive cells formed a diagonal arising from the $\mathrm{B}-\mathrm{CAM} / \mathrm{LU}$ plot, suggesting that individual $\mathrm{RBC}$ B-CAM/LU expression and the degree of laminin binding were directly correlated. However, a correlation was not found between laminin binding and expression of another RBC membrane adhesion molecule, CD44. Furthermore, when laminin binding was compared to staining with thiazole orange, a marker of reticulocytes, this pattern was also not seen (data not shown, three samples studied), even though blood from patients with SCD contains relatively high numbers of reticulocytes.

Expression of recombinant B-CAM induces laminin binding. When murine erythroleukemia (MEL) cells were stably transfected with either vector alone or vector containing $\mathrm{B}-\mathrm{CAM}$ cDNA, the $\mathrm{Lu}^{\mathrm{b}}$ antigen was easily detected in the transfectants containing B-CAM cDNA but not in cells containing vector alone (Fig. $7 A$ ). When transfected cells were tested for their ability to bind soluble laminin, laminin bound to $0.8 \%$ of MEL cells transfected with vector alone. $(0.4 \%$ of untransfected cells bound laminin.) In contrast, laminin bound to $15.7 \%$ of MEL cells expressing recombinant B-CAM (rBCAM) (Fig. 7 B). Solid phase assay of the same transfectants showed that $\mathrm{rB}-\mathrm{CAM}$ reacted with anti-B-CAM/LU and bound immobilized laminin $\left(\mathrm{OD}_{405}=0.534 \pm 0.028, P=0.004\right.$ vs vector alone), while cells transfected with vector alone did $\operatorname{not}\left(\mathrm{OD}_{405}=0.071 \pm 0.002\right)$. 
A

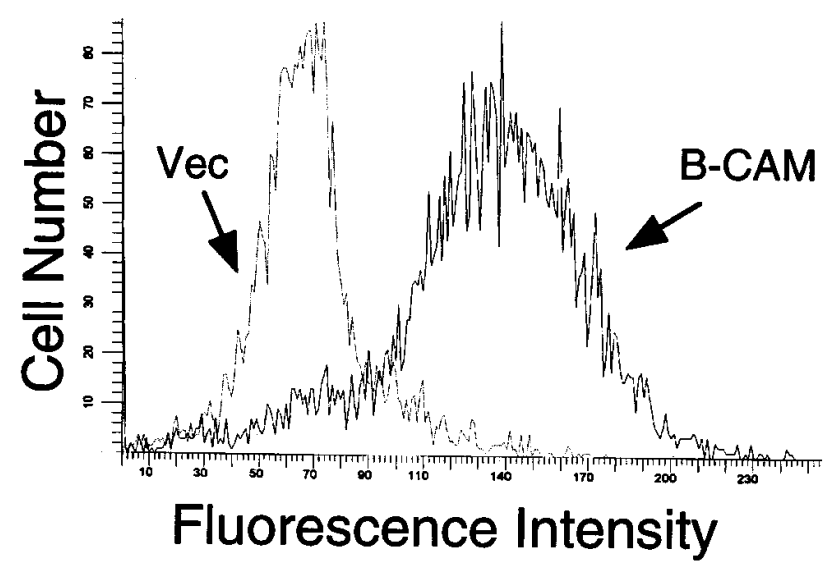

B

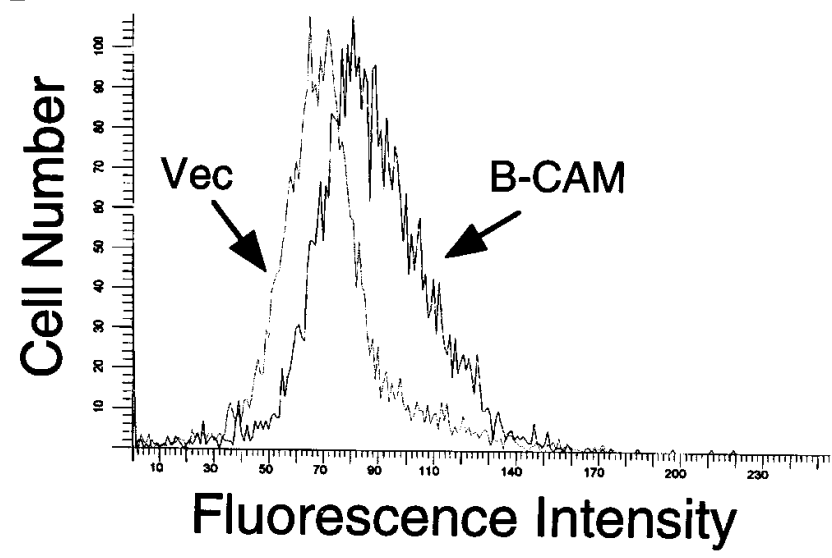

Figure 7. B-CAM expression and laminin binding by transfected MEL cells. $(A)$ Binding of anti-Lub to MEL cells transfected with B-CAM cDNA (B-CAM, dark line) and vector alone (vec, light line). Mean fluorescence channel (MFC) of all cells $=136.7$ and 64.2, respectively. (B) Binding of soluble laminin to MEL cells transfected with B-CAM cDNA (dark line) or vector alone (light line). MFC of all cells $=85.8$ and 67.2 , respectively.

The expression of rB-CAM by MEL cells also induced strong adhesion to immobilized laminin in the flow chamber assay. In multiple experiments, MEL cells expressing rB-CAM adhered to immobilized laminin with critical shear stresses $>15$ dyne $/ \mathrm{cm}^{2}$, while MEL cells expressing vector DNA only adhered with an average critical shear stress of 5.25 dyne $/ \mathrm{cm}^{2}$. Representative experiments are shown in Fig. 8.

\section{Discussion}

We have used assays measuring binding of both soluble and immobilized laminin to determine the identity of the major laminin binding protein of SS RBC. Our data indicate that the human RBC LU proteins, the smaller spliceoform of which has also been called B-CAM, bind laminin. Soluble laminin binds only to B-CAM/LU protein in lysates of RBC membranes, as clearly shown by ligand blots using RBC lacking B-CAM/LU. Moreover, our data support the hypothesis that, for SS RBC, both soluble and immobilized laminin bind to the same receptor. In solid phase assays, B-CAM/LU was again identified as the only significant ligand for laminin, irrespective of whether the laminin was bound in soluble or immobilized form. Thus, while B-CAM/LU becomes another protein in the rather long list of adhesion molecules expressed but functionally inactive on normal erythrocytes, B-CAM/LU is now the first such molecule shown to exhibit abnormal activity in a disease state.

In our studies, the degree of laminin binding to RBC was proportional to the strength of $\mathrm{B}-\mathrm{CAM} / \mathrm{LU}$ expression, as measured by two antibodies to $\mathrm{B}-\mathrm{CAM} / \mathrm{LU}$ protein. This correlation again supports the role of $\mathrm{B}-\mathrm{CAM} / \mathrm{LU}$ as the major $\mathrm{RBC}$ laminin receptor. In immunofluorescence assays, B-CAM/ $\mathrm{LU}$ and the Lutheran antigen $\mathrm{Lu}^{\mathrm{b}}$, recognized by the mAbs 8H3 and LM342/767:31, respectively, appeared to be relatively overexpressed by SS RBC, when compared with normal RBC from African-American or Caucasian controls. Moreover, increased B-CAM/LU antigen expression was correlated with increased laminin binding for both AA and SS RBC. The increased laminin binding by SS RBC did not appear due to the reticulocytosis present in patients homozygous for hemoglobin $\mathrm{S}$, as cells identified as reticulocytes by thiazole orange staining also did not account for the majority of laminin-binding RBC in two-color flow cytometry (data not shown).

The etiology of the apparent overexpression of B-CAM/ LU and its activation to bind laminin on SS RBC remains undetermined. It is possible that the increased RBC production and turnover present in sickle cell disease results in overexpression of B-CAM/LU by mature RBC, perhaps through an alteration of B-CAM/LU expression at the level of transcription during erythroid differentiation. Since B-CAM/LU is normally expressed by mature RBC (unlike the transferrin receptor and other surface markers of reticulocytes that are lost as $\mathrm{RBC}$ age), increased B-CAM/LU synthesis during stress erythropoiesis could result in increased B-CAM/LU expression by mature RBC, such as is seen with the "i" antigen. However, the degree of overexpression appears relatively small. Perhaps, therefore, increased copy number affects activation through a process such as homotypic aggregation, which occurs more readily with a higher copy number.

Or, the altered cell development present in stress erythropoiesis could result in an abnormal pattern of B-CAM/LU premRNA splicing, leading to relative overexpression of the $78-\mathrm{kD}$ form, as suggested by the Western blot results. There is reason to speculate that the $78-\mathrm{kD}$ form (originally described as B-CAM) may have a higher affinity for laminin, as it is the predominant form found at the basal surface of normal epithelial cells (18).

Another alternative hypothesis is that the apparent increased level of expression, as measured by immunofluorescence assays, as well as the increased ability to bind laminin that B-CAM/LU exhibits on SS RBC, may both be due to modification of the SS RBC membrane that occurs during cell circulation and deoxygenation. Hebbel and colleagues (36-38) have shown that denaturation of $\mathrm{Hb} \mathrm{S}$ leads to the deposition of hemichromes and free iron along the cytoplasmic surface of the membrane. Such a process has been shown to occur through protein oxidation, protein crosslinking, and lipid redistribution and may be responsible for a variety of alterations of SS RBC membrane characteristics. Activation through alteration of the cytoplasmic domain has previously been shown 


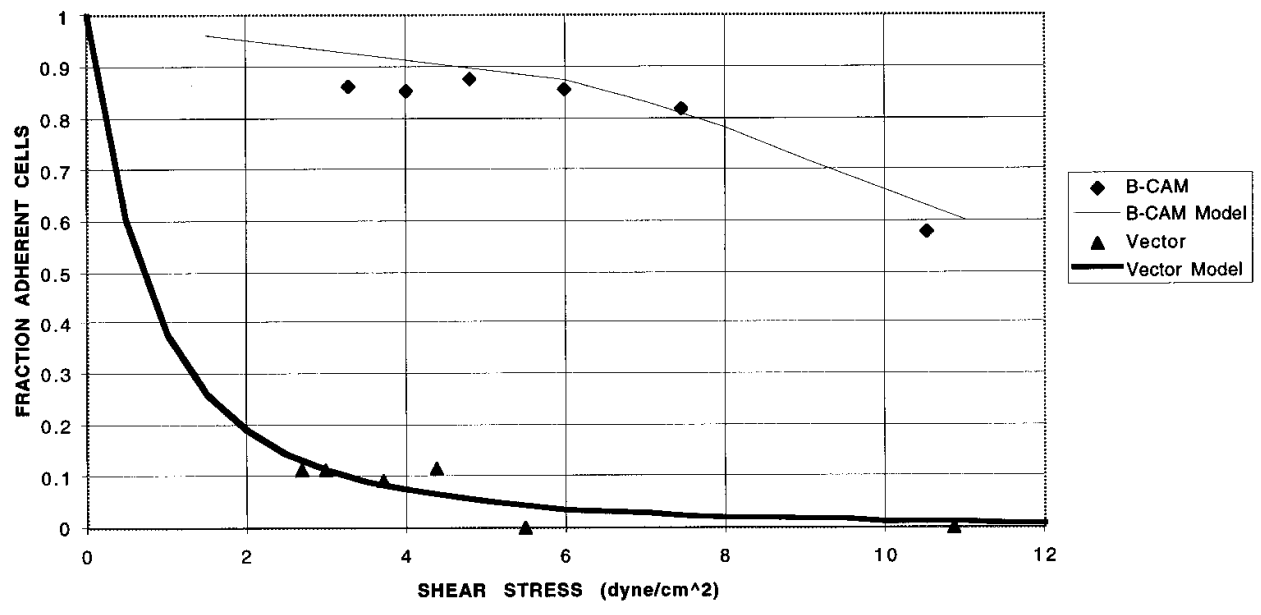

Figure 8. Adhesion of MEL cells with and without expression of rB-CAM to immobilized laminin. MEL cells transfected with vector only or with a vector encoding expression of B-CAM (rB-CAM) were assayed for their ability to adhere to immobilized laminin in the flow chamber assay. MEL cells expressing $\mathrm{rB}-\mathrm{CAM}$ adhered to immobilized laminin with a critical shear stress of $>15$ dyne $/ \mathrm{cm}^{2}$, while MEL cells expressing vector only adhered with an average critical shear stress of 5.25 dyne $/ \mathrm{cm}^{2}$. to occur in other adhesion molecules, including CD44 (the hyaluronan receptor) and integrins (39-41).

Identification of B-CAM/LU as the laminin receptor of SS $\mathrm{RBC}$ now opens up the possibility of determining what process leads to acquisition of the laminin-binding phenotype by SS $\mathrm{RBC}$ and investigation of the physiological importance of laminin binding to the overall process of vasoocclusion in SCD. Further, knowledge of the SS RBC laminin receptor structure should also allow development of inhibitors of receptor function. Such inhibitors will be useful both for in vitro investigations of SS RBC adhesion, as well as perhaps eventually for in vivo trials of the clinical efficacy of blocking this pathway as a means of modulating the vasoocclusive process in sickle cell disease. However, given the multiple measurable parameters that appear to contribute to the clinical course of sickle cell disease (e.g., activation of coagulation, presence of circulating endothelial cells, $\mathrm{Hb} \mathrm{F}$ level, and presence of one- and two-gene deletion alpha thalassemia), it is likely that only a large longitudinal clinical study and multivariate analysis will be able to determine the clinical significance of increased RBC binding to laminin in humans.

It is also interesting to speculate on the possible effect of the previously described increased expression of B-CAM/LU by epithelial tumor cells (18). Laminin is known to affect both the ability of some cancer cells to metastasize as well as the growth characteristics of some cancer cells (42). It remains to be seen whether overexpression of the larger B-CAM/LU spliceoform, which is a protein with a $S r c$ homology 3 binding domain in its cytoplasmic tail, contributes to an increased growth rate of epithelial cancer cells.

\section{Acknowledgments}

The authors would like to express their thanks to Sharon Hall for expert technical assistance with flow cytometry; Daria Peace and Patricia Thomas for their help in obtaining blood samples from sickle cell disease patients; and Andrea Pitkus, for technical assistance. We are also grateful to John Weeks for assistance with computer graphics.

This work was performed with funds from RO1 HL-33572 and RO1 HL-58939 from the National Heart, Lung and Blood Institute, National Institutes of Health, and from a Focused Giving Award from Johnson \& Johnson, Inc.

\section{References}

1. Embury, S.H., R.P. Hebbel, M.H. Steinberg, and N. Mohandas. 1994. Pathogenesis of vasoocclusion. In Sickle Cell Disease: Basic Principles and Clinical Practice, S.H. Embury, et al., editors. 1994, Raven Press, New York. 311-326.

2. Hoover, R., R. Rubin, G. Wise, and R. Warren. 1979. Adhesion of normal and sickle erythrocytes to endothelial monolayer cultures. Blood. 54:872876 .

3. Hebbel, R.P., O. Yamada, C.F. Moldow, H.S. Jacob, J.G. White, and J.W. Eaton. 1980. Abnormal adherence of sickle erythrocytes to cultured vascular endothelium: possible mechanism for microvascular occlusion in sickle cell disease. J. Clin. Invest. 65:154-160.

4. Brittain, H.A., J.R. Eckman, and T.M. Wick. 1992. Sickle erythrocyte adherence to large vessel and microvascular endothelium under physiologic flow is qualitatively different. J. Lab. Clin. Med. 120:538-545.

5. Sowemimo-Coker, S.O., H.J. Meiselman, and R.B. Francis, Jr. 1989. Increased circulating endothelial cells in sickle cell crisis. Am. J. Hematol. 31:263-265.

6. Hebbel, R.P., and N. Mohandas. 1994. Sickle cell adherence. In Sickle Cell Disease: Basic Principles and Clinical Practice. S.H. Embury, et al., editors. Raven Press, New York. 217-234.

7. Aumailley, M., and T. Kreig. 1996. Laminins: a family of diverse multifunctional molecules of basement membranes. J. Invest. Dermatol. 106:209-214.

8. Hillery, C.A., M.C. Du, R.R. Montgomery, and J.P. Scott. 1996. Increased adhesion of erythrocytes to components of the extracellular matrix: isolation and characterization of a red blood cell lipid that binds thrombospondin and laminin. Blood. 87:4879-4886.

9. Telen, M.J., M. Udani, M.K. Washington, M.C. Levesque, E. Lloyd, and N. Rao. 1996. A blood group-related polymorphism of CD44 abolishes a hyaluronan-binding consensus sequence without preventing hyaluronan binding. $J$. Biol. Chem. 271:7147-7153.

10. Hale, L.P., K.H. Singer, and B.F. Haynes. 1989. CD44 antibody against $\ln (\mathrm{Lu})$-related p80, lymphocyte-homing receptor molecule inhibits the binding of human erythrocytes to T cells. J. Immunol. 143:3944-3948.

11. Bailly, P., P. Hermand, I. Callebaut, H.H. Sonneborn, S. Khamlichi, J.P. Mornon, J.P. Cartron. 1994. The LW blood group glycoprotein is homologous to intercellular adhesion molecules. Proc. Natl. Acad. Sci. USA. 91:5306-5310.

12. Bailly, P., E. Tontti, P. Hermand, J.P. Cartron, and C.G. Gahmberg. 1995. The red cell LW blood group protein is an intercellular adhesion molecule which binds to CD11/CD18 leukocyte integrins. Eur. J. Immunol. 25:33163320 .

13. Gao, A.G., F.P. Lindberg, M.B. Finn, S.D. Blystone, E.J. Brown, and W.A. Frazier. 1996. Integrin-associated protein is a receptor for the C-terminal domain of thrombospondin. J. Biol. Chem. 271:21-24.

14. Lindberg, F.P., D.M. Lublin, M.J. Telen, R.A. Veile, Y.E. Miller, H. Donis-Keller, and E.J. Brown. 1994. Rh-related antigen CD47 is the signaltransducer integrin-associated protein. J. Biol. Chem. 269:1567-1570.

15. Gelin, C., F. Aubrit, A. Phalipon, B. Raynal, S. Cole, M. Kaczorek, and A. Bernard. 1989. The E2 antigen, a 32 kd glycoprotein involved in T-cell adhesion processes, is the MIC2 gene product. Embo J. 8:3253-3259.

16. Banting, G.S., B. Pym, S.M. Darling, and P.N. Goodfellow. 1989. The MIC2 gene product: epitope mapping and structural prediction analysis define an integral membrane protein. Mol. Immunol. 26:181-188.

17. Goodfellow, P.N., B. Pym, C. Pritchard, N. Ellis, M. Palmer, M. Smith, 
and P.J. Goodfellow. 1988. MIC2: a human pseudoautosomal gene. Philos. Trans. R. Soc. Lond. B. Biol. Sci. 322:145-154.

18. Campbell, I.G., W.D. Foulkes, G. Senger, J. Trowsdale, P. Garin-Chesa, and W.J. Rettig. 1994. Molecular cloning of the B-CAM cell surface glycoprotein of epithelial cancers: a novel member of the immunoglobulin superfamily. Cancer Res. 54:5761-5765.

19. Parsons, S.F., G. Mallinson, C.H. Holmes, J.M. Houlihan, K.L. Simpson, W.J. Mawby, N.K. Spurr, D. Warne, A.N. Barclay, and D.J. Anstee. 1995. The Lutheran blood group glycoprotein, another member of the immunoglobulin superfamily, is widely expressed in human tissues and is developmentally regulated in human liver. Proc. Natl. Acad. Sci. USA. 92:5496-5500.

20. Rahuel, C., C. Le Van Kim, M.G. Mattei, J.P. Cartron, and Y. Colin. 1996. A unique gene encodes spliceoforms of the B-cell adhesion molecule cell surface glycoprotein of epithelial cancer and of the Lutheran blood group glycoprotein. Blood. 88:1865-1872.

21. Gee, B., and O.S. Platt. 1995. CD44 may be a laminin receptor of normal and sickle erythrocytes. Blood. 86(Suppl.1): $137 a$.

22. Parsons, S.F., G. Mallinson, P.A. Judson, D.J. Anstee, M.J. Tanner, and G.L. Daniels. 1987. Evidence that the Lub blood group antigen is located on red cell membrane glycoproteins of 85 and $78 \mathrm{kd}$. Transfusion. 27:61-63.

23. El Nemer, W., C. Rahuel, Y. Colin, P. Gane, J.P. Cartron, and C. Le Van Kim. 1997. Organization of the human LU gene and molecular basis of the $\mathrm{Lu}^{\mathrm{a}} / \mathrm{Lu}^{\mathrm{b}}$ blood group polymorphism. Blood. 89:4608-4616.

24. Telen, M.J., G.S. Eisenbarth, and B.F. Haynes. 1983. Human erythrocyte antigens. Regulation of expression of a novel erythrocyte surface antigen by the inhibitor Lutheran $\ln (\mathrm{Lu})$ gene. J. Clin. Invest. 71:1878-1886.

25. Rao, N., M. Udani, J. Nelson, M.E. Reid, and M.J. Telen. 1995. Investigations using a novel monoclonal antibody to the glycosylphosphatidylinositolanchored protein that carries Gregory, Holley, and Dombrock blood group antigens. Transfusion. 35:459-464.

26. Galfre, G., S.C. Howe, C. Milstein, G.W. Butcher, and J.C. Howard. 1977. Antibodies to major histocompatibility antigens produced by hybrid cell lines. Nature. 266:550-552.

27. Petty, A.C. 1993. Monoclonal antibody-specific immobilisation of erythrocyte antigens (MAIEA). A new technique to selectively determine antigenic sites on red cell membranes. J. Immunol. Methods. 161:91-95.

28. Telen, M.J., T.J. Palker, and B.F. Haynes. 1984. Human erythrocyte antigens: II. The $\ln (\mathrm{Lu})$ gene regulates expression of an antigen on an 80-kilodalton protein of human erythrocytes. Blood. 64:599-606.

29. Laemmli, U.K. 1970. Cleavage of structural proteins during the assem- bly of the head of bacteriophage T4. Nature. 227:680-685.

30. Dodge, J.T., C. Mitchell, and D.J. Hanahan. 1963. The preparation and chemical characteristics of hemoglobin-free ghosts of human erythocytes. Arch. Biochem. Biophys. 100:119-130.

31. Towbin, H., T. Staehelin, and J. Gordon. 1979. Electrophoretic transfer of proteins from polyacrylamide gels to nitrocellulose sheets: procedure and some applications. Proc. Natl. Acad. Sci. USA. 76:4350-4354.

32. Xiao, Y., and G.A. Truskey. 1996. The effect of receptor-ligand affinity on the strength of adhesion of endothelial cells to immobilized RGD peptides and adsorbed fibronectin. Biophys. J. 71:2869-2884.

33. Jalkanen, S., and M. Jalkanen. 1992. Lymphocyte CD44 binds the COOH-terminal heparin-binding domain of fibronectin. J. Cell Biol. 116:817825

34. Telen, M.J., I. Rogers, and M. Letarte. 1987. Further characterization of erythrocyte $\mathrm{p} 80$ and the membrane protein defect of $\ln (\mathrm{Lu}) \mathrm{Lu}(\mathrm{a}-\mathrm{b}-)$ erythrocytes. Blood. 70:1475-1481.

35. Telen, M.J., and A.M. Green. 1988. Human red cell antigens. V. Expression of $\ln (\mathrm{Lu})$-related $\mathrm{p} 80$ antigens by recessive-type $\mathrm{Lu}(\mathrm{a}-\mathrm{b}-)$ red cells. Transfusion. 28:430-434.

36. Hebbel, R.P., W.T. Morgan, J.W. Eaton, and B.E. Hedlund. 1988. Accelerated autoxidation and heme loss due to instability of sickle hemoglobin. Proc. Natl. Acad. Sci. USA. 85:237-241.

37. Hebbel, R.P., A. Leung, and N. Mohandas. 1990. Oxidation-induced changes in microrheologic properties of the red blood cell membrane. Blood. 76:1015-1020.

38. Hebbel, R.P. 1991. Beyond hemoglobin polymerization: the red blood cell membrane and sickle disease pathophysiology. Blood. 77:214-237.

39. Liao, H.X., M.C. Levesque, K. Patton, B. Bergamo, D. Jones, M.A. Moody, M.J. Telen, and B.F. Haynes. 1993. Regulation of human CD44H and $\mathrm{CD} 44 \mathrm{E}$ isoform binding to hyaluronan by phorbol myristate acetate and antiCD44 monoclonal and polyclonal antibodies. J. Immunol. 151:6490-6499.

40. Gille, J., and R.A. Swerlick. 1996. Integrins: role in cell adhesion and communication. Ann. NY. Acad. Sci. 797:93-106.

41. Sjaastad, M.D., and W.J. Nelson. 1997. Integrin-mediated calcium signaling and regulation of cell adhesion by intracellular calcium. Bioessays. 19: $47-55$.

42. Kleinman, H.K., B.S. Weeks, H.W. Schnaper, M.C. Kibbey, K. Yamamura, and D.S. Grant. 1993. The laminins: a family of basement membrane glycoproteins important in cell differentiation and tumor metastases. Vitam. Horm. 47:161-186. 